\title{
Terrestrial nutrient exports and environmental changes explain eutrophication trends in fifty large lakes of Yangtze Plain, China
}

\section{Qi Guan}

School of Environmental Science and Engineering, Southern University of Science and Technology, Shenzhen, Guangdong, China.

\section{Jing Tang}

Department of Physical Geography and Ecosystem Science, Lund University, Lund, Sweden.

\section{Lian Feng ( $\nabla$ fengl@sustech.edu.cn )}

School of Environmental Science and Engineering, Southern University of Science and Technology, Shenzhen, Guangdong, China.

\section{Stefan Olin}

Department of Physical Geography and Ecosystem Science, Lund University, Lund, Sweden.

\section{Guy Schurgers}

Department of Geosciences and Natural Resource Management, University of Copenhagen, Copenhagen, Denmark.

\section{Research Article}

Keywords: Eutrophication, LPJ-GUESS, Terrestrial nutrient exports, Fertilizer, Yangtze Plain

Posted Date: January 25th, 2022

DOI: https://doi.org/10.21203/rs.3.rs-1280737/v1

License: (c) (i) This work is licensed under a Creative Commons Attribution 4.0 International License. Read Full License 


\section{Yangtze Plain, China}

3 Qi Guan ${ }^{\text {a, b }}$, Jing Tang ${ }^{\mathrm{c}, ~ d}$, Lian Feng ${ }^{\mathrm{a}, *}$, Stefan Olin ${ }^{\mathrm{c}}$, Guy Schurgers ${ }^{\mathrm{b}}$

4 a School of Environmental Science and Engineering, Southern University of Science and Technology, Shenzhen 5 518055, Guangdong, China.

$6 \quad{ }^{\mathrm{b}}$ Department of Geosciences and Natural Resource Management, University of Copenhagen, Copenhagen, Denmark.

$7 \quad{ }^{\mathrm{c}}$ Department of Physical Geography and Ecosystem Science, Lund University, Lund, Sweden.

$8 \quad{ }^{\mathrm{d}}$ Department of Biology, University of Copenhagen, Copenhagen, Denmark.

$9 \quad *$ corresponding author: fengl@sustech.edu.cn

\section{Abstract}

Over the past two decades, lakes in Yangtze Plain have suffered from serious eutrophication, in some regions with increased frequency of cyanobacteria blooms over years. In this study, we investigated the underlying causes of eutrophication using a combination of process-based ecosystem modelling and statistical data analysis. We found that terrestrial nutrient exports with runoff have significantly increased from 1979 to 2018 in Yangtze Plain, directly linked to the enhanced usage of chemical fertilizer for crops. Based on statistical analyses of environmental variables, terrestrial nutrient exports and satellite-observed probability of eutrophication occurrence (PEO), we separated the studied fifty lakes into five classes with similarities in environmental and nutrient variations, and attributed key factors in controlling the temporal changes of PEO. The results showed that the satellite-observed PEO trends in five classes could be largely linked to the terrestrial nutrient exports and environmental changes. Specifically, we found agricultural activities can explain the observed eutrophication trends in western lakes where lake catchments are dominated with arable and natural land, and the reduced discharge of industrial wastewater was found to be linked to the declining trends in eutrophication for eastern lakes where the green growth of industrialization were promoted from 2003 to 2011. These findings highlight the importance of sustainable management of agriculture and industrialization to overcome eutrophication issues in this region.

Keywords: Eutrophication, LPJ-GUESS, Terrestrial nutrient exports, Fertilizer, Yangtze Plain

\section{Introduction}

Eutrophication in the Earth's surface waters has become a global environmental concern (Sinha et al. 2017), which 
has been mainly linked to nutrient over-enrichment, mainly nitrogen $(\mathrm{N})$ and phosphorus $(\mathrm{P})$ elements because they can greatly accelerate phytoplankton growth and development (Beman et al. 2005; Gooddy et al. 2016). Concurrent with eutrophication, algal blooms are demonstrated to occur at high intensity and frequency globally (Schindler et al. 2008; Wilhelm et al. 2011), which have resulted in negative impacts on ecological, societal and economic systems, such as water quality deterioration, biological habitat damages and freshwater resource shortage (Guan et al. 2020; Lewis et al. 2011). Cyanobacteria can be able to release toxic substances for competing light and survival resources with other phytoplankton, which, however, poisons water bodies, especially inland lakes and reservoirs to threaten water availability as drinking water sources and destroy food chains in acquatic ecosystems (Paerl et al. 2011; Zhao et al. 2019).

As a typical example of human-environment interaction, Yangtze Plain also witnessed frequent eutrophication under great anthropogenic stresses (Hong et al. 2021; Liu et al. 2020). Analysis based on satellite imagery has found that severe eutrophication has largely changed water environments in most lakes on the Yangtze Plain (Guan et al. 2020; Ma et al. 2010). Frequent cyanobacteria blooms polluted water quality in Taihu and Chaohu Lake and threatened drinking water safety for millions of citizen in local cities (Guo 2007; Huang et al. 2019; Shi et al. 2015). Although local governments have made great efforts to monitor and control eutrophication (Xu et al. 2015), cyanobacteria blooms still occur at increased frequency, indicating that there are missing processes and/or unquantified nutrient sources at landscape scale.

Many previous studies have attempted to track the causes of eutrophication on the Yangtze Plain at the level of individual lake, such as in Taihu and Chaohu (Huang et al. 2020; Zou et al. 2020). Wang et al. (2019b) distinguished that diffuse nitrogen sources from agricultural and urban systems contributed $90 \%$ to river nitrogen exports, while point sources contributed $52 \%$ to river phosphorus exports in Taihu Lake based on in-situ measurements. The temporal dynamics of algal blooms were primarily associated with nutrient (total dissolved nitrogen and phosphorus) concentration in Taihu Lake from 1993 to 2015 (Zhang et al. 2018). Moreover, the nitrogen and phosphorus concentration in lakes were monitored as discrete points to demonstrate the roles of nutrient loads in eutrophication changes of several lakes (Dai et al. 2016; Liang et al. 2020; Tong et al. 2017; Yindong et al. 2021). Unfortunately, these previous findings only focused on individual and several hyper-eutrophic lakes for short periods, which made it difficult to provide comprehensive understanding of factors in regulating regional patterns of lake eutrophication. Furthermore, plants actively participate in terrestrial water and nutrient cycling, and these abovementioned studies 
cannot consider the dynamic roles of terrestrial ecosystems in influencing runoff and leached nutrients from land to lakes.

To fill these two knowledge gaps mentioned above, we employed a process-based dynamic vegetation model, LPJGUESS together with statistical analysis to reveal how terrestrial ecosystem processes are linked to regional patterns of eutrophication. More specifically, we aim to: 1) quantify temporal and spatial patterns of terrestrial nutrient exports to fifty large lakes in the Yangtze Plain for the past forty years; 2) determine linkages between the changes in nutrient and environment variables, and satellite-observed eutrophication changes; and 3) analyze the overall driving factors for regional eutrophication for the period from 2003 to 2011 in the Yangtze Plain.

\section{Materials and Methods}

\subsection{Study area}

The Yangtze Plain (Fig. 1), located in the middle and lower basin of Yangtze River, covers a total area of $\sim 7850000$ $\mathrm{km}^{2}$ from Hunan Province to Shanghai City and has been experiencing rapid urbanization and economic growth (Feng et al. 2019; Hou et al. 2017). The region is characterized by the sub-tropical monsoon climate, with annual precipitation over $1000 \mathrm{~mm} / \mathrm{yr}$ and average temperatures around $15^{\circ} \mathrm{C}$. The abundant precipitation provides the main water source for $\sim 5900$ lakes and reservoirs (Guan et al. 2020; Guan et al. 2018). Yangtze Plain functions as one of top three grain-production bases (mainly grain and oil) in China. The total agricultural area is about 100 million hectares and produce approximately $54 \%$ of national grain yields (Chen et al. 2020). Such a huge agricultural system demands substantial chemical fertilizer to enhance grain yield to accommodate the rapid population growth (Zuo et al. 2018). Previous study has reported that there is generally low nitrogen use efficiency for crops, causing excessive nutrients leaching into local surface water (Zhang et al. 2015). Furthermore, rapid urbanization and economic growth has shrank arable lands, mainly on the eastern parts of Yangtze Plain, since the Reform and Opening-up of China (Chen et al. 2019; Zuo et al. 2018). The industrial and urban discharged wastewater should also be traced and analyzed in terms of their impacts on water environments in lakes of Yangtze Plain. 


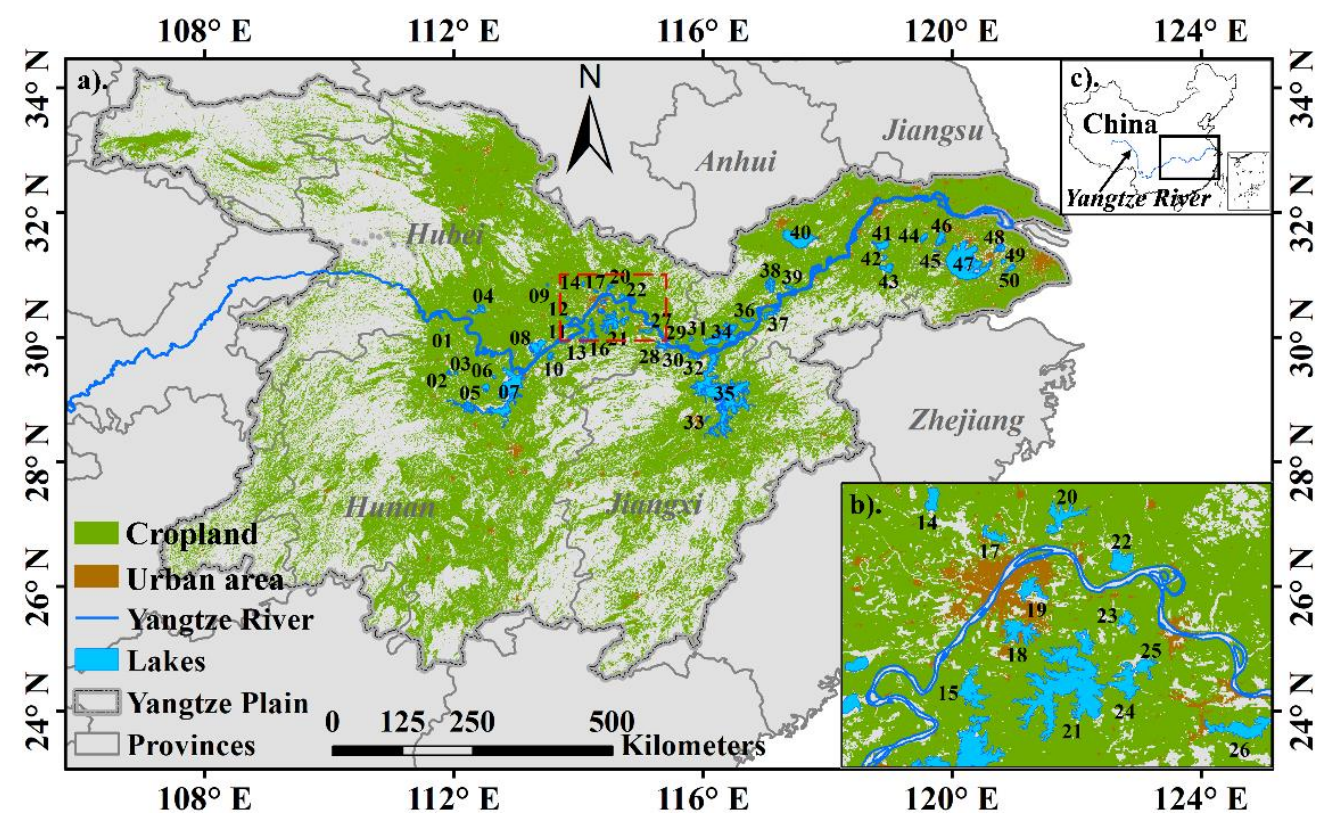

Figure 1. Locations of fifty large lakes in the Yangtze Plain, China. a). The numbers show the ID number of each studied lake, and names of each lake are listed in Table S2. b). The zoomed-in area of Wuhan region (red box) and the surrounding lakes. c). Locations of Yangtze River and Yangtze Plain in China.

\subsection{Dynamic vegetation model}

LPJ-GUESS, a dynamic vegetation model (Smith et al. 2001; Smith et al. 2014), was employed here to simulate vegetation dynamics, soil biogeochemistry, carbon and nitrogen cycling on Yangtze Plain. LPJ-GUESS is driven by daily climate data (i.e., temperature, precipitation and short-wave radiation), and has been widely used to simulate ecosystem carbon and nitrogen fluxes at regional to global scales (Smith et al. 2014). The model includes both natural plant functional types (PFTs) and crop function types (CFTs) to represent different types of plants and crops (Olin et al. 2015). Both PFTs and CFTs are characterized by different bio-climatic and physiological parameters, such as minimum/maximum growing temperatures, photosynthetic pathway, growth form, phenology, allometry, rates of establishment and mortality (Sitch et al. 2003; Smith et al. 2014), which determine their competitiveness for resources like light, water and nutrients and their productivity. The annual fractions of land use types and CFT distribution for each grid cell are read from input datasets. Crop management, including irrigation, fertilization and rotation schemes, are also applied for each CFT to represent agricultural practices (Olin et al. 2015).

In LPJ-GUESS, daily fluxes of carbon and nitrogen between ecosystems and the atmosphere are simulated, and for PFTs, daily net primary production (NPP) is accumulated through a year and allocated to different plant organs (leaves, fine roots, and stem) at the end of each year. The carbon allocation for crops (CFTs) occurs on a daily step 
and is influenced by daily NPP and crop development stages (Olin et al. 2015). Dead leaf, wood and root enter soil litter $\mathrm{C}$ and $\mathrm{N}$ pools. In the model, there are in total 11 soil carbon pools with different decomposition rates (Parton et al. 1993; Parton et al. 2010). The $\mathrm{C}$ and $\mathrm{N}$ transfers among the $\mathrm{C}$ pools are influenced by soil temperature, water content and C-N ratios of receiving pools (Smith et al. 2014). Vegetation takes up mineral N via roots for growth and development. Apart from plant uptake, soil $\mathrm{N}$ is influenced by atmospheric deposition, plant biological fixation, nutrient gaseous losses and decomposition of SOM, and can be leached with runoff in the forms of dissolved organic (DON) and inorganic (DIN) nitrogen. DON is computed daily as a fraction of the decomposition rate of the soil microbial SOM pool and is affected by percolation, while DIN is based on daily percolation and available mineral N.

Crops are initialized with $\mathrm{C}$ mass from seeds, they also have an initial $\mathrm{N}$ content based on the CFT's C: $\mathrm{N}_{\min }$ value. Fertilizer and manure were applied three times during the growing period and the application rates at each time were defined for each crop as fractions of the total application amount (Lindeskog et al. 2013). Daily carbon allocation varies with crop development status, defined as development stages in LPJ-GUESS, where details about carbon allocation at different development stages can be found in (Olin et al. 2015).

In this study, we used 11 CFTs to represent the majority of crops in Yangtze Plain. Hybrid and super-hybrid rice are widely distributed in this region, characterized by high grain yield in a short growing season. The high grain yield is associated with enhanced photosynthesis rates due to higher chlorophyll and Rubisco contents in leaves than normal rice (Yuan et al. 1998). Therefore, we calibrated the relationship between leaf $\mathrm{N}$ content and the maximum catalytic capacity of Rubisco (Vmax) in LPJ-GUESS via optimization of grain yield (Haxeltine and Prentice 1996).

$$
N=p V_{m}^{25}+N_{0}
$$

where $\mathrm{N}$ represents the foliage $\mathrm{N}$ content, $V_{m}^{25}$ is the maximum catalytic capacity of Rubisco at $25^{\circ} \mathrm{C} . p$ and $N_{0}$ are empirical parameters. The parameter, $p$, is largely reduced to increase the rubisco capacity for super-hybrid rice (Table A1). Furthermore, super-hybrid rice has higher a specific leaf area (SLA, in Table A1), compared with normal rice (Huang et al. 2016), which could benefit crop productivity via potentially more intercepted light through the canopy.

LPJ-GUESS runs on three land cover types (i.e., cropland, natural land and grassland) with a 500-year spin-up to perform land processes on Yangtze Plain from 1979 to 2018. Due to limited data before 1992 and after 2015, crop distributions, land cover fraction and terrestrial N application were kept constant at the 1992 level for the period 1979 
-1992 and at the 2015 level for the period after 2015.

\subsection{Study datasets.}

\subsubsection{LPJ-GUESS input datasets}

LPJ-GUESS input datasets include gridded climate, land cover fraction, chemical fertilizer and manure, gridded crop cultivation and soil properties. The climate data, daily air temperature, precipitation and shortwave radiation, were obtained from China Meteorological Forcing Dataset (CMFD) (He et al. 2020b), with a spatial resolution of $0.1^{\circ}$ and coverage from 1979 to 2018. The Climate Change Initiative Land Cover (CCI-LC version 2.0) dataset was used to derive annual land cover fractions of urban, cropland, pasture and natural area from 1992 to 2015 by regrouping the original 37 land cover classes with a spatial resolution of $300 \mathrm{~m}$ into these four fractions at a spatial resolution of 0.1 (Defourny et al. 2012) (for details see Section S1). Soil properties, consisting of sand, clay and silt fractions, organic carbon content, $\mathrm{C}: \mathrm{N}$ ratio, $\mathrm{pH}$ and bulk density, were extracted from the World Inventory of Soil property Estimates (WISE30sec) with a spatial resolution of 30" (Batjes 2016), which were resampled to a spatial resolution of $0.1^{\circ}$ based on the soil properties of the dominant FAO soil unit within a $0.1^{\circ}$ grid cell. The chemical fertilizer usage and manure $\mathrm{N}$ data were both derived from global chemical fertilizer usage data from 1961 to 2013 published by (Lu

Crop cultivation datasets, including crop type distribution, sowing and harvesting dates of crops, were interpolated

\subsubsection{Evaluation of LPJ-GUESS}

Three types of datasets were used to evaluate the performance of LPJ-GUESS simulation: 1) GOSIF GPP product; 2) GIMMS LAI3g product, and 3) field-observed grain yield. The annual global GOSIF GPP products from 1992 to 2018 were produced by (40), which has a spatial resolution of $0.05^{\circ}$ (Li and Xiao 2019). The annual GIMMS LAI3g 
products cover the period of 1982 to 2011, with a spatial resolution of $0.25^{\circ}$ (Zhu et al. 2013). The observed annual grain yield for ten main crops was obtained from 89 stations across the Yangtze Plain from 2000 to 2018 (Liu et al. 2010). Due to limited yield data for each crop, the average grain yield for each crop type was calculated to represent regional mean grain yield for comparison with simulated grain yield in Yangtze Plain.

\subsubsection{Eutrophication data}

173 Satellite-derived PEO published in Guan et al. (2020) is defined as the occurrence frequency of high chlorophyll-a concentration $\left(>10 \mathrm{mg} \mathrm{m}^{-3}\right)$ or algal blooms for each study year. In details, for each lake pixel, the number of images with high chlorophyll-a concentration or algal blooms was divided with total valid MERIS observations of each year to get the annual PEO value. For the fifty study lakes in Yangtze Plain, the PEO values of lake pixels within each lake were averaged to get lake averaged PEO value to represent eutrophication status and changes in fifty large studied lakes in Yangtze Plain from 2003 to 2011. The PEO dataset has been used in the statistical analysis together with nutrient and environmental variables.

\subsubsection{Other auxiliary datasets}

The considered terrestrial P sources come from chemical fertilizer and manure, which were determined from global phosphorus fertilizer products and biological excrement (Lu and Tian 2017; Zhang et al. 2017). Manure phosphorus

\subsection{Statistical analysis}

190 We applied statistical analyses for determining possible drivers of the satellite-observed PEO changes. Seven explanatory variables (listed in Table S4) were used in a principal component analysis (PCA), including terrestrial nutrient exports and environmental factors. PCA was employed to assess how different variables are related from 2003 to 2011. For the PCA analysis, Z-score normalization was used (across all years and lakes) to remove the 
194 influence of different magnitudes between explanatory variables. The first two principal components (PCs) were

subsequently used to separate the studied lakes into five different classes using K-mean clustering (Krishna and Murty 1999), where the dominant class of each lake for the studied period was used for the classification. Finally, partial least-squared regression (PLSR) was used to assess the drivers of PEO in the five identified classes, where data samples in all studied lakes were also normalized by Z-scores in SIMCA 17 (Umetrics, version 13.0.3.0, Umeå, Sweden). Explanatory variables with a VIP (Variable Influence on Projection) $<0.5$ were removed, and variance of the cross-validated residuals was considered for testing whether the PLSR model was statistically significant for each lake class.

\section{Results and Discussion}

\subsection{Model evaluation}

To evaluate the performance of LPJ-GUESS model, the simulated annual crop yield, leaf area index (LAI) and gross primary production (GPP) were compared with observation-based estimates. The crop yields for ten main crop types, averaged for the Yangtze Plain area, agreed well with observed values, with both mean relative errors (MRE) and root mean squared errors (RMSE) between simulated and observed grain yields lower than 10\% (Fig. 2). Similar spatial patterns appeared between the simulated and satellite-derived LAI and GPP estimates (Fig. S2). The magnitudes of simulated LAI were in good agreement with GIMMS LAI3g estimates (Fig. S1a), while LPJ-GUESS overall underestimated GPP compared with GOSIF GPP (underestimation on average 20\%, Fig. S1b). Estimations of LAI for all grid cells showed a satisfactory accuracy with a MRE of $\sim 15 \%$ and RMSE of $27 \%$. Simulated LAI distributed mainly along the 1:1 line with GIMMS LAI3g, and overestimations were most pronounced in areas with large cropland fractions. Nevertheless, the overall accuracy of simulated GPP is considered acceptable for such a regional simulation with relatively low MRE and RMSE ( 23\%). 


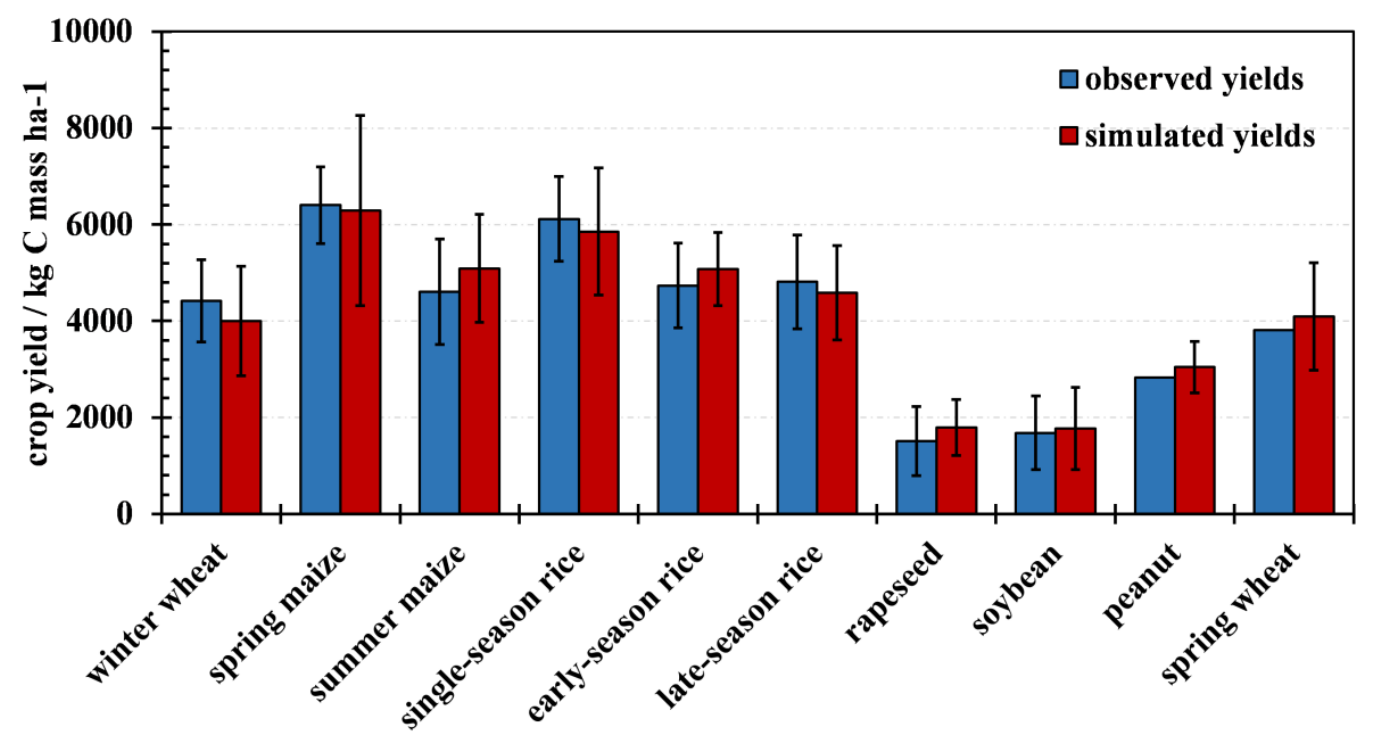

218 Figure 2. Comparison between the simulated and observed grain yield for ten main crops, averaged for crop 219 productivity in Yangtze Plain from 2000 to 2015. Error bars show \pm 1 standard deviation of all available grain yields.

220 Observed grain yield for peanut and spring wheat are literature values (He et al. 2020a; Yao 2004).

\subsection{Growing anthropogenic nutrient application in Yangtze Plain}

223 The total $\mathrm{N}$ and $\mathrm{P}$ applications from chemical fertilizer and manure have clearly increased over the past forty years 224 (Fig. 3), with average rates of $2.75 \mathrm{~kg} \mathrm{~N} \mathrm{ha}^{-1} \mathrm{yr}^{-2}$ and $0.51 \mathrm{~kg} \mathrm{P} \mathrm{ha}^{-1} \mathrm{yr}^{-2}$, respectively, resulting in a three-fold increase 225 over the study period. However, due to differences in the paces of the two elements, the N:P ratio shows a decreasing trend combined with strong fluctuation in the period until 2000 and a slight rise or stabilization for the last 15 years (Fig. 3), potentially reshaping soil and water nutrient over-enrichment in Yangtze Plain.
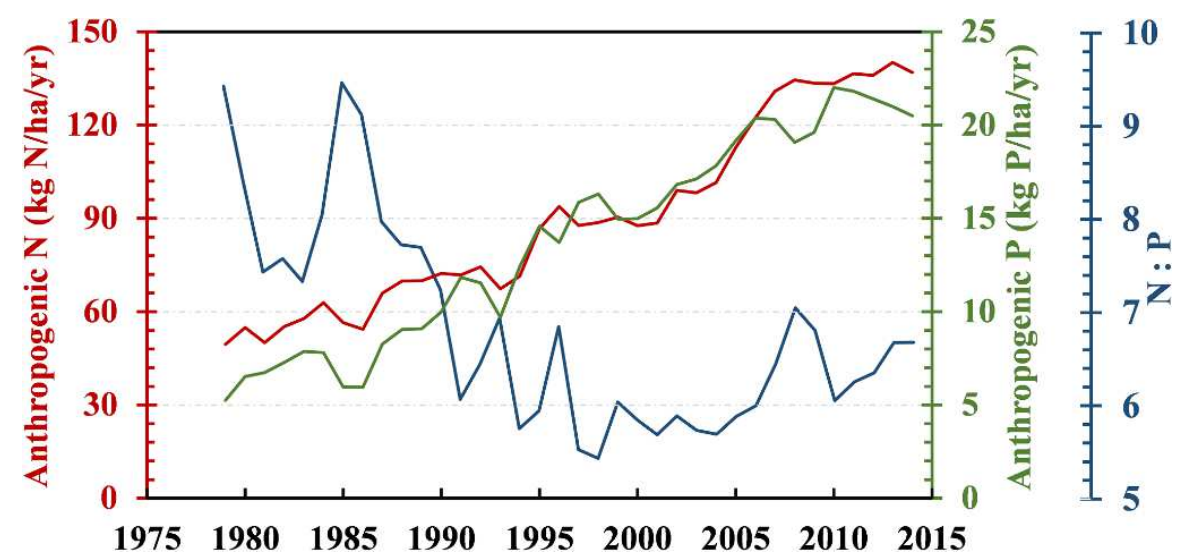

Figure 3. The annual inputs of anthropogenic nitrogen $(\mathrm{N})$ and phosphorus $(\mathrm{P})$ from chemical fertilizers and manure and their corresponding N:P ratio from 1979 to 2014. Data were averaged across the whole Yangtze Plain. 
234 We used LPJ-GUESS to simulate and quantify the impact of this enhanced application of fertilizer and manure on 235 the nutrient surplus leached as potential nutrient sources for lake water eutrophication. In the Yangtze Plain, the 236 simulated leached $\mathrm{N}$ from agricultural and natural land has increased significantly during the study period, with a considerably lower rate for natural $\left(\sim 0.2 \mathrm{~kg} \mathrm{~N} \mathrm{ha}^{-1} \mathrm{yr}^{-2}\right.$, Fig. $\left.4 \mathrm{~b}\right)$ than for agricultural ecosystems $\left(\sim 4.5 \mathrm{~kg} \mathrm{~N} \mathrm{ha}^{-1} \mathrm{yr}^{-}\right.$ $2382^{2}$, Fig. 4a), due to external inputs from fertilizer and manure to the latter. Considerable spatial differences in $\mathrm{N}$ 239 leaching from cropland (CLN) and natural land (NLN) existed. Higher N leaching was simulated for the cropland 240 area in the catchment of Dongting Lake (longitude range $110^{\circ} \mathrm{E}$ to $114^{\circ} \mathrm{E}$ ), which was linked to higher fertilizer rates. 241 A decrease of N leaching was simulated in the eastern parts of Yangtze Plain (Fig. 4c). NLN distributed differently 242 between the south and north sides of Yangtze Plain (Fig. 4d), mainly because of differences in N sources from 243 atmospheric deposition and biological fixation under different climatic conditions (Zhan et al. 2017).

Individually, all studied lake catchments were characterized by significantly increasing trends for CLN, but with different start points for the CLN increases (Fig. 4e): The CLN values for lake catchments in the western region (L01L06) started to increase already around 1990, much earlier than the catchments for eastern lakes (L45-L50, starting approximately 2005), suggesting that the nutrient status in western lakes to be potentially affected earlier than in eastern lakes. Similarly, NLN for all studied lake catchments, except for Donghu Lake (L18), has significantly increased with generally lower rates than CLN values over the past forty years (Fig. 4f). Seven lake catchments dominated by natural vegetation exhibited higher NLN (i.e., L28, L30, L32, L35, L37, L38, L43) than the surrounding lakes, collectively distributed in the middle regions of Yangtze Plain (near Poyang Lake). 

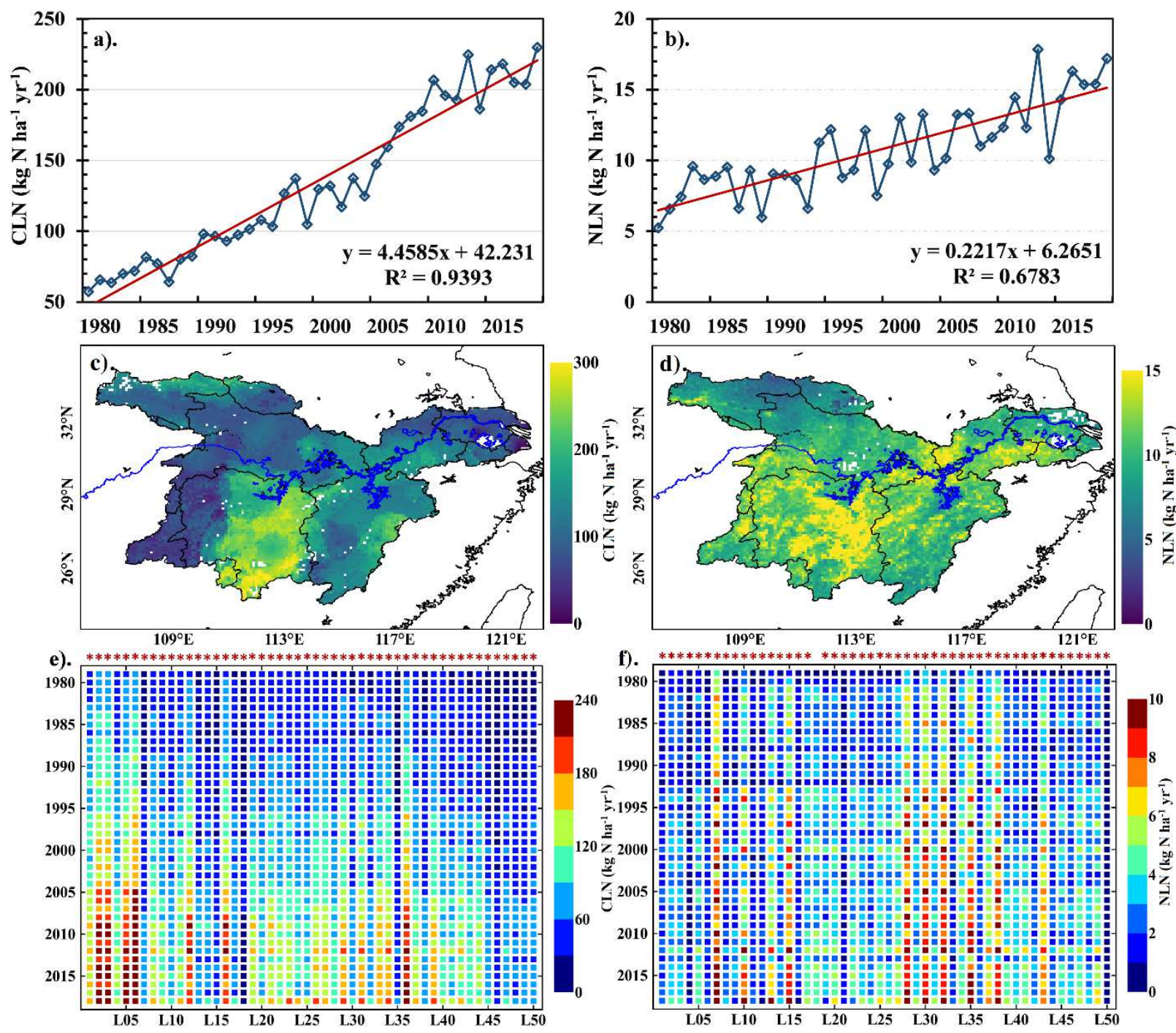

Figure 4. Temporal and spatial patterns of leached $\mathrm{N}$ from cropland (CLN) and natural area (NLN). a) and b):

Temporal changes of CLN and NLN, where solid red lines are linear trends between years and leached N. Rates are

expressed per area cropland and natural land, respectively. c) and d): Spatial patterns of CLN and NLN expressed

per total catchment area (mean for 1979-2018), respectively. e) and f): Inter-annual changes of mean CLN and NLN

values averaged over lake catchment area from 1979-2018, with statistically significantly increased trends (Mann

Kendall trend test, $p<0.05$ ) annotated with '*'. The ID numbers of lakes are listed in Table S2.

\subsection{Linking nutrient and environmental drivers with PEO changes}

262 To understand the potential impacts of environmental factors and terrestrial nutrient inputs on lake eutrophication status, the modelled CLN, NLN, the observation-based anthropogenic P exports (AP), N-P ratio (NP) and industrial wastewater discharge (IW), together with potential environmental drivers temperature (T) and total runoff (TR), were investigated as potential drivers of lake eutrophication. Annual mean values of these drivers for 2003-2011 were 
combined with satellite-observed PEO over fifty lakes of Yangtze Plain from. We first used principal component analysis (PCA) to group the 50 lakes into different classes based on the abovementioned seven driving factors, and then we employed partial least-squared regression (PLSR) models on these classes to quantify the potential contribution of nutrient and environmental factors to the changes of PEO. The PCA results showed that the first two principal components (PCs) explained $35.7 \%$ and $24.6 \%$ of variations in environmental and nutrient exports between lakes and years (Fig. 5a), where the first PC primarily consists of positive correlations with agriculture-related nutrients (i.e., CLN, NP and AP) and negative correlations with TR, NLN and IW, and the second PC reveals a positive dependence on TR, T, NLN and AP, but negative dependence on IW. Based on these two PCs, we grouped fifty lakes into five classes with similar nutrient and environmental drivers using a K-means method (Krishna and Murty 1999) (see Method sections for details). Although all five classes were characterized with high mean PEO ( $>$ $80 \%$, Fig. 5 b) and considerable variability around the means, different magnitudes of trends in the study period were found between classes. PEO values for the majority of the lakes in class II decreased with time, while the other classes were dominated by increasing trends of PEO, with the strongest increases occurring in class III (Fig. 5c). Lakes of Class II are mainly located at the eastern parts of Yangtze Plain, where lake catchments undergo rapid industrialization. Lakes and their associated catchments of Class III cover a large area of Yangtze Plain (50.6\%) and include the two largest lakes of this region (i.e., Poyang Lake, L35 and Dongting Lake, L07 in Fig. 1). The PEO changes in this class are positively linked to NLN and TR, showing the large influences from natural area and land runoff. Totally, 12 lakes were clustered into Class I, aligning closely with AP, CLN and T, and 14 lakes, mainly distributed in the middle reach of Yangtze Plain, were clustered into Class IV, with some impacts from AP. Lakes of Class V with large fractions of cropland aligned with CLN and NP, and most of these lakes were located in the agriculture-dominated western parts of Yangtze Plain, especially in Hunan Province (Fig. 1).
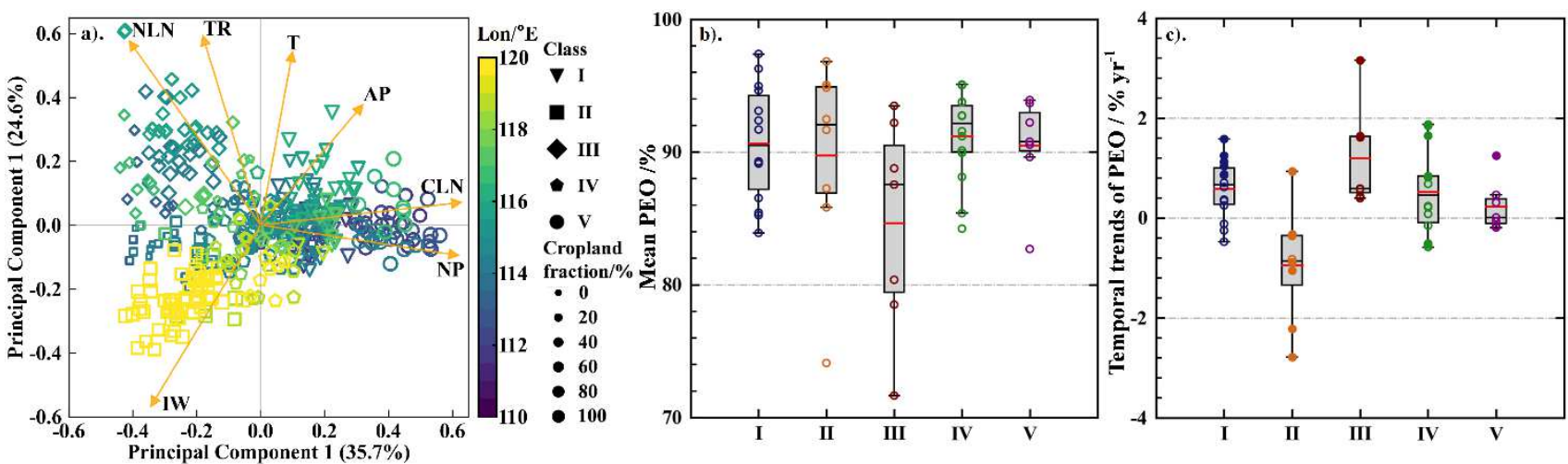

Figure 5. Principal component analysis classifying lake eutrophication with the same drivers. a). Loading plots of 
principal component analysis (PCA) based on seven explanatory variables. The color and size of scattering points represent the distribution of lakes on longitudinal orders and cropland fraction within lake catchments, respectively.

292 The directions of explanatory variables were annotated with orange lines. b) and c) mean values and temporal trends of PEO from 2003 to 2011 in five derived classes, where colored circles represent mean values and temporal trend trends as hollow circles based on Mann-Kendall trend analysis with the threshold value of $p$ as 0.05 in $\mathbf{c}$ ). Red and black solid lines are mean and median values, respectively. The bottom and top of the boxes represent first and third quartile, and error bars are the 95\% confidence intervals. CLN: cropland leached nitrogen; NLN: nature leached nitrogen; AP: anthropogenic phosphorus; NP: nitrogen-phosphorus ratio; IW: industrial wastewater; T: temperature;

Significant PLSR models between annual values of PEO and drivers for all lakes within each class were found for all five classes ( $p<0.05$, Fig 6), and for each class, different drivers were responsible for the PEO changes. Across all lakes (Fig. 6f), we found PEO variations to be positively linked to agricultural nutrients NP and CLN, but negatively linked to NLN, highlighting that agricultural activities could be responsible to the overall changes of lake PEO in Yangtze Plain. At the class level, Class II showed clear positive linkage of PEO with IW and T, but negative linkage to the agricultural related indices (i.e., CLN, NP \&AP) and total runoff, and the PEO changes for all other classes appear to be positively linked to the agricultural activities. In Class II, the lakes are dominated by negative trends of PEO (Fig. 5c), and the PLSR model provides many possible drivers for this (Fig. 6b). The decreasing trends in IW (Fig. S5) are expected to be the mechanistic driver of PEO dynamics, while for the other four variables with significantly negative coefficients and positive trends in each variable (Fig. S5), the PLSR model provides correlations between these explanatory variables and PEO in Class II lakes that are mechanistically unlikely (Fig. 5c). Furthermore, the large magnitude of IW changes observed in Class II lakes might suggest that the decreasing trends of PEO were mainly explained by the decreased exports of IW for the study period (Fig. S5), and that increased export of nutrients from cropland, although correlated, counterbalances this effect. Green industrial growth and wastewater treatment plants seem to have efficiently limited nutrient exports to local water bodies (Lyu et al. 2016). Notably, the attribution of driving factors to PEO changes based on these five classes could also be influenced by the spatial variations among lakes within each class, as the lakes have been grouped based on the dominant environmental and nutrient variables (PCA results). Therefore, we further examined the temporal trends of the significant factors and PEO for each lake within the same class (Fig. S5) to see if there are large variations among lake individuals 
within the same class. We found that lakes within the same class often showed similar trends in explanatory variables and PEO as indicated by the regression coefficients in the PLSR models. For instance, the positive coefficients between PEO and IW in Class II lakes (Fig. 6b) were also seen as negative trends for both PEO and IW when we look at individual lakes. These alignments of trends and correlations support that the environmental and nutrient variables are mainly linked to the inter-annual changes in PEO in these five classes (Fig. S5). For Class III, there are different trends of $\mathrm{T}$ and $\mathrm{PEO}$, although they showed positive coefficients, which in this case, indicates potential impacts from spatial variability of lakes in this class.
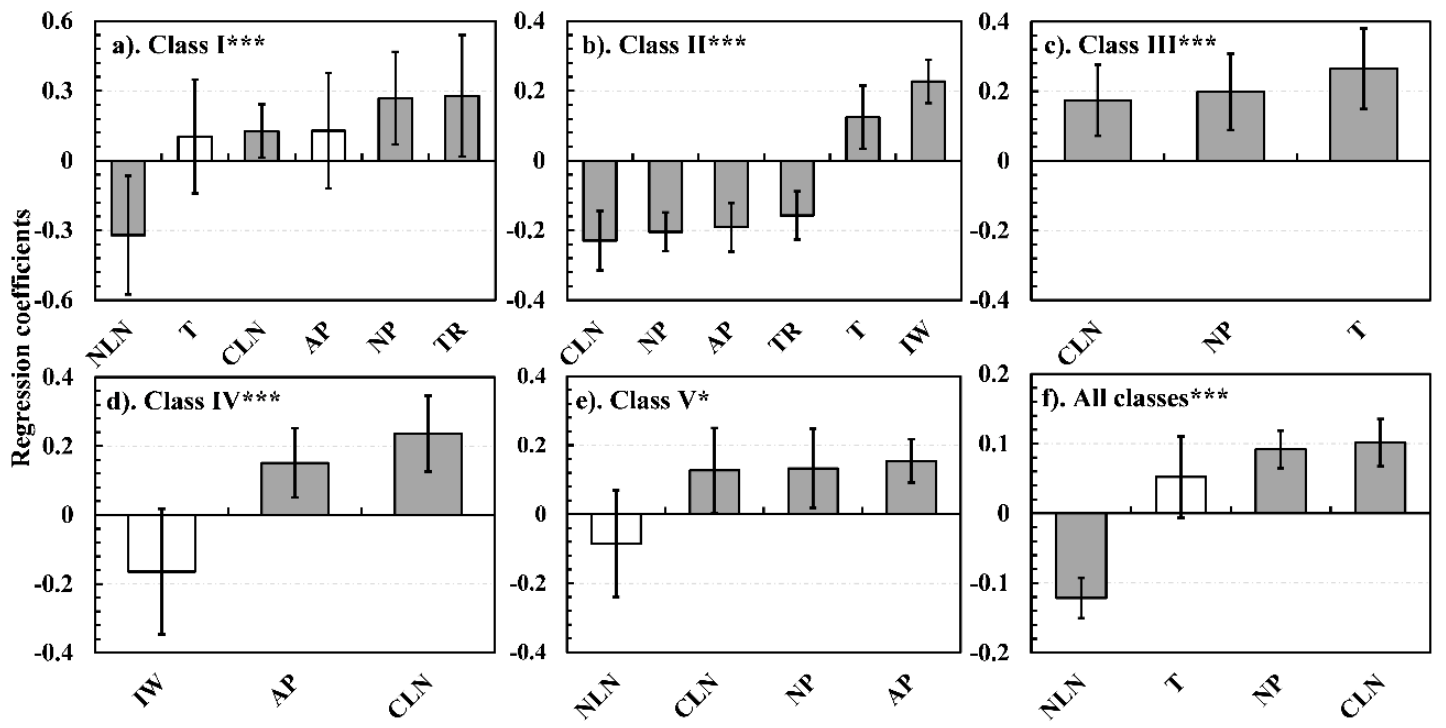

Figure 6. Regression coefficients of PLSR model between PEO and seven explanatory variables. a-e are class I-V, and $\mathbf{f}$ is all fifty studied lakes. Statistically significant models (CV-ANOVA) are annotated as $* * *$ for $p<0.001$ and $*$ for $p<0.05$. Error bars represent \pm 2 standard deviations of PLSR regression coefficients. CLN: cropland leached nitrogen; NLN: nature leached nitrogen; AP: anthropogenic phosphorus; NP: nitrogen-phosphorus ratio; IW: industrial wastewater; T: temperature; TR: total runoff.

\subsection{Contributions of anthropogenic activities to eutrophication}

In this study, we have attempted to determine possible causes of PEO for studied lakes using statistical methods. The results from these methods alone are unavoidably influenced by the correlations between individual variables, and/or by similar long-term trends in several explanatory variables that do not differ greatly between studied lake catchments. In such cases, the used statistical methods may result in correlations that do not allow differentiating between possible underlying mechanisms. 
342 Through our analysis, we found out that lake eutrophication in Yangtze Plain is mainly associated with anthropogenic stresses, consisting of agriculture and industrialization. Industrialization-affected eutrophic lakes collectively distribute in the eastern parts of Yangtze Plain, while agricultural activities have large impacts on middle and western lake catchments with large cropland distribution in the catchments, most of which are located upstream of Dongting Lake (L7 in Fig. 4). Some lakes in the middle parts are characterized by PEO changes induced via large variability of land cover fraction, including two river-connected lakes (i.e., Dongting and Poyang Lake) for which PEO dynamics were not only affected by drivers in the local catchment, but also by upstream land use changes (Dai et al. 2017; Li et al. 2014). Current fertilizer usage in this region seems to largely exceed the demands for crop growth resulting in substantial nutrient exports to water bodies stimulating algae and phytoplankton growth (Zhang et al. 2015). The average $\mathrm{N}$ use efficiency simulated by LPJ-GUESS was about $34 \%$ in this region, which is much lower than the targeted goal of $60 \%$ for sustainable developments in China (Zhang et al. 2015). By maintaining high yield levels for food requirements of growing population (Long et al. 2018; Zhang et al. 2015), increasing use efficiency of chemical fertilizer in the agricultural area should be the main focus in this region to improve water quality in lakes of Yangtze Plain (Wang et al. 2019a).

Industrialization and economic growth can also contribute to increase nutrient exports available for phytoplankton communities mainly through industrial wastewater discharges (Wang et al. 2019b). Jiangsu Province, located in the eastern part of Yangtze Plain, experienced industrialization and economic development with annual industrialization and economic growth rates of $0.98 \%$ and $7.98 \%$, respectively (Shen et al. 2020; Wang et al. 2020b). Under this rapid development, the decreased IW found in this region is on one hand associated with the national strategies and policies about green growth of industries, which encouraged industrial reuse and invested to advance wastewater treatment technology and installation of municipal wastewater treatment plants (Li et al. 2013; Lyu et al. 2016). On the other hand, the industrial structure transformation from secondary to tertiary industries also contributed to improve eutrophication status by decreasing industrial sewage discharge (Huang et al. 2015).

\subsection{Limitations and Uncertainties}

Terrestrial $\mathrm{N}$ and $\mathrm{P}$ sources were considered as nutrient elements for phytoplankton growth and development (Yi et al. 2017; Zhou et al. 2018). Unfortunately, most of the existing large-scale vegetation/ecosystem models lack of Prelated processes in soil and vegetation (Che et al. 2014; Kerr and Wigneron 2020). We expect that leached P depends 
on not only P fertilizer use, but also plant uptakes and soil supplies, similar to N processes (Fig. S6), which suggests that a further consideration of ecosystem processes on leached $\mathrm{P}$ and $\mathrm{PEO}$ will be needed. The $\mathrm{P}$ manure data, generated from $\mathrm{N}$ manure data via N-P ratios in animal excrements, are not fully independent from $\mathrm{N}$ manure inputs but are still important to include here as the nutrient sources in order to assess the contributions of P exports (i.e., chemical fertilizer and manure) from agricultural systems to surface water eutrophication ( $\mathrm{Li}$ et al. 2017). Terrestrial nutrient sources are transported with runoff into local lakes, where part of these become accessible for phytoplankton. The lateral runoff and transport processes of terrestrial nutrients are influenced by soil properties, topography, and hydrological conditions (Solomon et al. 2015; Tang et al. 2015; Tang et al. 2014; Tang et al. 2018) which need to be further accounted for in order to assess the amount and dynamics of terrestrial nutrients into local lakes (Solomon et al. 2015). Apart from terrestrial nutrient sources, intensive aquaculture distributing across Yangtze Plain can be a potential nutrient source for water eutrophication (Luo et al. 2018; Wang et al. 2020a). Seventeen out of 50 Yangtze lakes have established enclosure fishery nets to increase fish production (Dai et al. 2019), where substantial amounts of fish baits were directly cast into aquaculture area for feeding fish. The surplus nutrients enable to contribute to more severe eutrophication (Guo and Li 2003). These limitations will need to be further explored to obtain a complete picture of nutrient sources available for phytoplankton communities and to reduce anthropogenic impacts on lake water quality and eutrophication.

\section{Conclusion}

In this study, we combined a dynamic vegetation model LPJ-GUESS with statistical analysis to reveal factors controlling eutrophication status in fifty large Yangtze lakes. During the past forty years, the agriculture-related nutrient exports (N\&P) have significantly increased for all studied lakes, mainly linked to the enhanced chemical fertilizer usage. The leached nitrogen from natural land are much smaller than cropland. The averaged nitrogen leaching from cropland in the catchment of Dongting Lake is apparently greater than the middle- and eastern- parts of Yangtze Plain, while the leached nitrogen from natural land revealed considerable spatial variations from the north to south sides of Yangtze Plain linked to different climatic conditions. The overall PEO trends in the studied lakes were largely explained by the discharged industrial wastewater and leached nutrients from agricultural systems. There are spatial variations in terms of controlling factor responsible to the observed trends, for instance, nine lakes on the eastern Yangtze Plain were influenced by industrial wastewater, while most of lakes in the western Yangtze Plain, especially in Hunan Province, were relevant to agriculture activities. This study highlighted the roles of anthropogenic activities in water quality degradation and water pollution. Additionally, the approach of combining process-based 
ecosystem model with satellite data to understand eutrophication changes could be applied on other regions and/or at larger scales, such as national and global scale, to provide critical information for policy-making to improve water environments

\section{Acknowledgments}

This work was supported by the National Natural Science Foundation of China (NOs: 41971304). Qi Guan was funded by the SUSTech-UCPH Joint Program. Jing Tang was financially supported by Swedish FORMAS mobility grant (2016-01580). Stefan Olin acknowledges support from Lund University strong research areas MERGE and eSSENCE. We would like to appreciate European Space Agency (ESA) for publishing land cover dataset, China Meteorological Data Service Center for providing crop distribution and yield data.

\section{Reference}

Batjes, N.H. (2016). Harmonized soil property values for broad-scale modelling (WISE30sec) with estimates of global soil carbon stocks. J Geoderma, 269, 61-68

Beman, J.M., Arrigo, K.R., \& Matson, P.A.J.N. (2005). Agricultural runoff fuels large phytoplankton blooms in vulnerable areas of the ocean, 434, 211-214

Che, M.-L., Chen, B.-Z., Wang, Y., \& Guo, X.-Y. (2014). Review of dynamic global vegetation models (DGVMs). Ying yong sheng tai xue bao= The journal of applied ecology, 25, 263-271

Chen, C., Park, T., Wang, X., Piao, S., Xu, B., Chaturvedi, R.K., Fuchs, R., Brovkin, V., Ciais, P., Fensholt, R., Tømmervik, H., Bala, G., Zhu, Z., Nemani, R.R., \& Myneni, R.B. (2019). China and India lead in greening of the world through land-use management. Nature Sustainability, 2, 122-129

Chen, X., Wang, L., Niu, Z., Zhang, M., Li, C.a., \& Li, J. (2020). The effects of projected climate change and extreme climate on maize and rice in the Yangtze River Basin, China. Agricultural and Forest Meteorology, 282-283

Dai, M., Wang, J., Zhang, M., \& Chen, X.J.I.J.o.S.R. (2017). Impact of the Three Gorges Project operation on the water exchange between Dongting Lake and the Yangtze River, 32, 506-514

Dai, X., Qian, P., Ye, L., \& Song, T. (2016). Changes in nitrogen and phosphorus concentrations in Lake Taihu, 1985-2015. J Lake Sci, 28, 935-943

Dai, Y., Feng, L., Hou, X., Choi, C.Y., Liu, J., Cai, X., Shi, L., Zhang, Y., \& Gibson, L. (2019). Policy-driven changes in enclosure fisheries of large lakes in the Yangtze Plain: Evidence from satellite imagery. Sci Total Environ, 688, 1286-1297

Defourny, P., Kirches, G., Brockmann, C., Boettcher, M., Peters, M., Bontemps, S., Lamarche, C., Schlerf, M., \& Santoro, M.J.P.U.G.V. (2012). Land cover CCl, 2

Feng, L., Hou, X., \& Zheng, Y. (2019). Monitoring and understanding the water transparency changes of fifty large lakes on the Yangtze Plain based on long-term MODIS observations. Remote Sensing of Environment, 221, 675-686

Gooddy, D.C., Lapworth, D.J., Bennett, S.A., Heaton, T.H.E., Williams, P.J., \& Surridge, B.W.J. (2016). A multi-stable isotope framework to understand eutrophication in aquatic ecosystems. Water Res, 88, 623-633

Guan, Q., Feng, L., Hou, X., Schurgers, G., Zheng, Y., \& Tang, J. (2020). Eutrophication changes in fifty large lakes on the Yangtze Plain of China derived from MERIS and OLCl observations. Remote Sensing of Environment, 246

Guan, Q., Feng, L., \& Kuang, X. (2018). Optical Classifications of Poyang Lake Water and Long-Term Dynamics Based on 

Guo, L. (2007). Ecology. Doing battle with the green monster of Taihu Lake. Science, 317, 1166

Guo, L., \& Li, Z. (2003). Effects of nitrogen and phosphorus from fish cage-culture on the communities of a shallow lake in middle Yangtze River basin of China. J Aquaculture, 226, 201-212

He, D., Fang, S., Liang, H., Wang, E., \& Wu, D.J.E.R.L. (2020a). Contrasting yield responses of winter and spring wheat to temperature rise in China, 15, 124038

He, J., Yang, K., Tang, W., Lu, H., Qin, J., Chen, Y., \& Li, X. (2020b). The first high-resolution meteorological forcing dataset for land process studies over China. Sci Data, 7, 25

Hong, C., Burney, J.A., Pongratz, J., Nabel, J.E., Mueller, N.D., Jackson, R.B., \& Davis, S.J.J.N. (2021). Global and regional drivers of land-use emissions in 1961-2017, 589, 554-561

Hou, X., Feng, L., Duan, H., Chen, X., Sun, D., \& Shi, K. (2017). Fifteen-year monitoring of the turbidity dynamics in large lakes and reservoirs in the middle and lower basin of the Yangtze River, China. Remote Sensing of Environment, 190, 107121

Huang, C., Zhang, M., Zou, J., Zhu, A.-X., Chen, X., Mi, Y., Wang, Y., Yang, H., \& Li, Y. (2015). Changes in land use, climate and the environment during a period of rapid economic development in Jiangsu Province, China. Science of The Total Environment, 536, 173-181

Huang, C., Zhang, Y., Huang, T., Yang, H., Li, Y., Zhang, Z., He, M., Hu, Z., Song, T., \& Zhu, A.X. (2019). Long-term variation of phytoplankton biomass and physiology in Taihu lake as observed via MODIS satellite. Water Res, 153, 187-199

Huang, J., Zhang, Y., Arhonditsis, G.B., Gao, J., Chen, Q., \& Peng, J. (2020). The magnitude and drivers of harmful algal blooms in China's lakes and reservoirs: A national-scale characterization. Water Res, 181, 115902

Huang, M., Shan, S., Zhou, X., Chen, J., Cao, F., Jiang, L., \& Zou, Y. (2016). Leaf photosynthetic performance related to higher radiation use efficiency and grain yield in hybrid rice. Field Crops Research, 193, 87-93

Kerr, Y.H., \& Wigneron, J.-P. (2020). Vegetation models and observations A review. Passive microwave remote sensing of land-atmosphere interactions (pp. 317-344): De Gruyter

Krishna, K., \& Murty, M.N. (1999). Genetic K-means algorithm. IEEE Transactions on Systems, Man, and Cybernetics, Part $B$ (Cybernetics), 29, 433-439

Lewis, W.M., Wurtsbaugh, W.A., \& Paerl, H.W. (2011). Rationale for control of anthropogenic nitrogen and phosphorus to reduce eutrophication of inland waters. Environ Sci Technol, 45, 10300-10305

Li, A.A., Strokal, M.M., Bai, Z.Z.H., Kroeze, C.C., Ma, L.L., \& Zhang, F.F.S. (2017). Modelling reduced coastal eutrophication with increased crop yields in Chinese agriculture \%J Soil Research, 55, 506-517

Li, H.-M., Tang, H.-J., Shi, X.-Y., Zhang, C.-S., \& Wang, X.-L.J.H.A. (2014). Increased nutrient loads from the Changjiang (Yangtze) River have led to increased harmful algal blooms, 39, 92-101

Li, X., \& Xiao, J. (2019). A Global, 0.05-Degree Product of Solar-Induced Chlorophyll Fluorescence Derived from OCO-2, MODIS, and Reanalysis Data. Remote Sensing, 11

Li, Y., Luo, X., Huang, X., Wang, D., \& Zhang, W. (2013). Life Cycle Assessment of a municipal wastewater treatment plant: a case study in Suzhou, China. Journal of Cleaner Production, 57, 221-227

Liang, Z., Soranno, P.A., \& Wagner, T. (2020). The role of phosphorus and nitrogen on chlorophyll a: Evidence from hundreds of lakes. Water Research, 185

Lindeskog, M., Arneth, A., Bondeau, A., Waha, K., Seaquist, J., Olin, S., \& Smith, B.J.E.S.D. (2013). Implications of accounting for land use in simulations of ecosystem carbon cycling in Africa, 4, 385-407

Liu, S., Mo, X., Lin, Z., Xu, Y., Ji, J., Wen, G., \& Richey, J. (2010). Crop yield responses to climate change in the Huang-HuaiHai Plain of China. Agricultural Water Management, 97, 1195-1209

Liu, X., Huang, Y., Xu, X., Li, X., Li, X., Ciais, P., Lin, P., Gong, K., Ziegler, A.D., \& Chen, A.J.N.S. (2020). High-spatiotemporal- 
resolution mapping of global urban change from 1985 to 2015, 3, 564-570

Long, S., Zhao, L., Shi, T., Li, J., Yang, J., Liu, H., Mao, G., Qiao, Z., \& Yang, Y.J.J.o.C.P. (2018). Pollution control and cost analysis of wastewater treatment at industrial parks in Taihu and Haihe water basins, China, 172, 2435-2442

Lu, C., \& Tian, H. (2017). Global nitrogen and phosphorus fertilizer use for agriculture production in the past half century: shifted hot spots and nutrient imbalance. Earth System Science Data, 9, 181-192

Luo, Z., Hu, S., \& Chen, D. (2018). The trends of aquacultural nitrogen budget and its environmental implications in China. Sci Rep, 8, 10877

Lyu, S., Chen, W., Zhang, W., Fan, Y., \& Jiao, W. (2016). Wastewater reclamation and reuse in China: opportunities and challenges. Journal of Environmental Sciences, 39, 86-96

Ma, R., Duan, H., Hu, C., Feng, X., Li, A., Ju, W., Jiang, J., \& Yang, G. (2010). A half-century of changes in China's lakes: Global warming or human influence? Geophysical Research Letters, 37

Olin, S., Schurgers, G., Lindeskog, M., Wårlind, D., Smith, B., Bodin, P., Holmér, J., \& Arneth, A. (2015). Modelling the response of yields and tissue $\mathrm{C}: \mathrm{N}$ to changes in atmospheric $\mathrm{CO} 2$ and $\mathrm{N}$ management in the main wheat regions of western Europe. Biogeosciences, 12, 2489-2515

Paerl, H.W., Xu, H., McCarthy, M.J., Zhu, G., Qin, B., Li, Y., \& Gardner, W.S. (2011). Controlling harmful cyanobacterial blooms in a hyper-eutrophic lake (Lake Taihu, China): the need for a dual nutrient (N \& P) management strategy. Water Res, 45, 1973-1983

Parton, W., Scurlock, J., Ojima, D., Gilmanov, T., Scholes, R., Schimel, D.S., Kirchner, T., Menaut, J.C., Seastedt, T., \& Garcia Moya, E.J.G.b.c. (1993). Observations and modeling of biomass and soil organic matter dynamics for the grassland biome worldwide, 7, 785-809

Parton, W.J., Hanson, P.J., Swanston, C., Torn, M., Trumbore, S.E., Riley, W., \& Kelly, R.J.J.o.G.R.B. (2010). ForCent model development and testing using the Enriched Background Isotope Study experiment, 115

Schindler, D.W., Hecky, R.E., Findlay, D., Stainton, M., Parker, B., Paterson, M., Beaty, K., Lyng, M., \& Kasian, S.J.P.o.t.N.A.o.S. (2008). Eutrophication of lakes cannot be controlled by reducing nitrogen input: results of a 37-year whole-ecosystem experiment, 105, 11254-11258

Shen, F., Yang, L., He, X., Zhou, C., \& Adams, J.M. (2020). Understanding the spatial-temporal variation of human footprint in Jiangsu Province, China, its anthropogenic and natural drivers and potential implications. Scientific reports, 10, 1-12 Shi, K., Zhang, Y., Xu, H., Zhu, G., Qin, B., Huang, C., Liu, X., Zhou, Y., \& Lv, H. (2015). Long-Term Satellite Observations of Microcystin Concentrations in Lake Taihu during Cyanobacterial Bloom Periods. Environ Sci Technol, 49, 6448-6456

Sinha, E., Michalak, A.M., \& Balaji, V. (2017). Eutrophication will increase during the 21st century as a result of precipitation changes, 357, 405-408

Sitch, S., Smith, B., Prentice, I.C., Arneth, A., Bondeau, A., Cramer, W., Kaplan, J.O., Levis, S., Lucht, W., \& Sykes, M.T.J.G.c.b. (2003). Evaluation of ecosystem dynamics, plant geography and terrestrial carbon cycling in the LPJ dynamic global vegetation model, 9, 161-185

Smith, B., Prentice, I.C., Sykes, M.T.J.G.e., \& biogeography (2001). Representation of vegetation dynamics in the modelling of terrestrial ecosystems: comparing two contrasting approaches within European climate space, 621-637

Smith, B., Wårlind, D., Arneth, A., Hickler, T., Leadley, P., Siltberg, J., \& Zaehle, S. (2014). Implications of incorporating N cycling and $\mathrm{N}$ limitations on primary production in an individual-based dynamic vegetation model. Biogeosciences, 11, 2027-2054

Solomon, C.T., Jones, S.E., Weidel, B.C., Buffam, I., Fork, M.L., Karlsson, J., Larsen, S., Lennon, J.T., Read, J.S., Sadro, S., \& Saros, J.E. (2015). Ecosystem Consequences of Changing Inputs of Terrestrial Dissolved Organic Matter to Lakes: Current Knowledge and Future Challenges. Ecosystems, 18, 376-389

Tang, J., Miller, P.A., Crill, P.M., Olin, S., \& Pilesjo, P. (2015). Investigating the influence of two different flow routing algorithms on soil-water-vegetation interactions using the dynamic ecosystem model LPJ-GUESS. Ecohydrology, 8, 570- 
Tang, J., Pilesjö, P., Miller, P.A., Persson, A., Yang, Z., Hanna, E., \& Callaghan, T.V.J.E. (2014). Incorporating topographic indices into dynamic ecosystem modelling using LPJ - GUESS, 7, 1147-1162 Tang, J., Yurova, A.Y., Schurgers, G., Miller, P.A., Olin, S., Smith, B., Siewert, M.B., Olefeldt, D., Pilesjo, P., \& Poska, A. (2018). Drivers of dissolved organic carbon export in a subarctic catchment: Importance of microbial decomposition, sorptiondesorption, peatland and lateral flow. Sci Total Environ, 622-623, 260-274 Tong, Y., Zhang, W., Wang, X., Couture, R.-M., Larssen, T., Zhao, Y., Li, J., Liang, H., Liu, X., Bu, X., He, W., Zhang, Q., \& Lin, Y. (2017). Decline in Chinese lake phosphorus concentration accompanied by shift in sources since 2006 . Nature Geoscience, 10, 507-511 Source of Nutrients in Chinese Freshwater and Coastal Seas. Environ Sci Technol, 54, 1464-1474

Wang, J., Fu, P., Wang, F., Fahad, S., Mohapatra, P.K., Chen, Y., Zhang, C., Peng, S., Cui, K., Nie, L., \& Huang, J. (2019a). Optimizing nitrogen management to balance rice yield and environmental risk in the Yangtze River's middle reaches. Environ Sci Pollut Res Int, 26, 4901-4912

Wang, M., Strokal, M., Burek, P., Kroeze, C., Ma, L., \& Janssen, A.B.G. (2019b). Excess nutrient loads to Lake Taihu: Opportunities for nutrient reduction. Sci Total Environ, 664, 865-873

Wang, Z., Zhao, L., \& Wang, Y. (2020b). An empirical correlation mechanism of economic growth and marine pollution: A case study of 11 coastal provinces and cities in China. Ocean \& Coastal Management, 198, 105380

Wilhelm, S.W., Farnsley, S.E., LeCleir, G.R., Layton, A.C., Satchwell, M.F., DeBruyn, J.M., Boyer, G.L., Zhu, G., \& Paerl, H.W. (2011). The relationships between nutrients, cyanobacterial toxins and the microbial community in Taihu (Lake Tai), China. Harmful Algae, 10, 207-215

Xu, H., Paerl, H.W., Qin, B., Zhu, G., Hall, N.S., \& Wu, Y. (2015). Determining critical nutrient thresholds needed to control harmful cyanobacterial blooms in eutrophic Lake Taihu, China. Environ Sci Technol, 49, 1051-1059

Yao, G.J.U.o.G. (2004). Peanut production and utilization in the People's Republic of China

Yi, Q., Chen, Q., Hu, L., \& Shi, W. (2017). Tracking Nitrogen Sources, Transformation, and Transport at a Basin Scale with Complex Plain River Networks. Environ Sci Technol, 51, 5396-5403

Yindong, T., Xiwen, X., Miao, Q., Jingjing, S., Yiyan, Z., Wei, Z., Mengzhu, W., Xuejun, W., \& Yang, Z. (2021). Lake warming intensifies the seasonal pattern of internal nutrient cycling in the eutrophic lake and potential impacts on algal blooms. Water Res, 188, 116570

Yuan, L., Denning, G., \& Mew, T.J.D.G., Mew TW, editors (1998). Hybrid rice breeding for super high yield, 10-12 Zhan, X., Bo, Y., Zhou, F., Liu, X., Paerl, H.W., Shen, J., Wang, R., Li, F., Tao, S., Dong, Y., \& Tang, X. (2017). Evidence for the Importance of Atmospheric Nitrogen Deposition to Eutrophic Lake Dianchi, China. Environmental Science \& Technology, $51,6699-6708$

Zhang, B., Tian, H., Lu, C., Dangal, S.R.S., Yang, J., \& Pan, S. (2017). Global manure nitrogen production and application in cropland during 1860-2014: a 5 arcmin gridded global dataset for Earth system modeling. Earth System Science Data, 9 , 667-678

Zhang, M., Shi, X., Yang, Z., Yu, Y., Shi, L., \& Qin, B. (2018). Long-term dynamics and drivers of phytoplankton biomass in eutrophic Lake Taihu. Sci Total Environ, 645, 876-886

Zhang, X., Davidson, E.A., Mauzerall, D.L., Searchinger, T.D., Dumas, P., \& Shen, Y.J.N. (2015). Managing nitrogen for sustainable development, 528, 51-59

Zhao, Z., Cao, Y., Fan, Y., Yang, H., Feng, X., Li, L., Zhang, H., Xing, L., \& Zhao, M. (2019). Ladderane records over the last century in the East China sea: Proxies for anammox and eutrophication changes. Water Res, 156, 297-304

Zhou, Y., Xiao, Q., Yao, X., Zhang, Y., Zhang, M., Shi, K., Lee, X., Podgorski, D.C., Qin, B., Spencer, R.G.M., \& Jeppesen, E. (2018). Accumulation of Terrestrial Dissolved Organic Matter Potentially Enhances Dissolved Methane Levels in Eutrophic 
571 Lake Taihu, China. Environ Sci Technol, 52, 10297-10306

572 Zhu, Z., Bi, J., Pan, Y., Ganguly, S., Anav, A., Xu, L., Samanta, A., Piao, S., Nemani, R.R., \& Myneni, R.B.J.R.s. (2013). Global 573 data sets of vegetation leaf area index (LAI) $3 \mathrm{~g}$ and fraction of photosynthetically active radiation (FPAR) $3 \mathrm{~g}$ derived from 574 global inventory modeling and mapping studies (GIMMS) normalized difference vegetation index (NDVI3g) for the period 5751981 to $2011,5,927-948$

576 Zou, W., Zhu, G., Cai, Y., Xu, H., Zhu, M., Gong, Z., Zhang, Y., \& Qin, B. (2020). Quantifying the dependence of cyanobacterial 577 growth to nutrient for the eutrophication management of temperate-subtropical shallow lakes. Water Research, 177

578 Zuo, L., Zhang, Z., Carlson, K.M., MacDonald, G.K., Brauman, K.A., Liu, Y., Zhang, W., Zhang, H., Wu, W., Zhao, X., Wang, X., 579 Liu, B., Yi, L., Wen, Q., Liu, F., Xu, J., Hu, S., Sun, F., Gerber, J.S., \& West, P.C. (2018). Progress towards sustainable 580 intensification in China challenged by land-use change. Nature Sustainability, 1, 304-313 


\section{Supplementary Files}

This is a list of supplementary files associated with this preprint. Click to download.

- SupplementaryMaterial.docx 